\title{
Application of Rose Bengal Test and ELISA in Meat Juice for Monitoring of Brucellosis among Cattle Carcasses at Erbil City, Iraq
}

\author{
Dhary Alewy AL - mashhadany \\ Knowledge University, College of Science, Department of Pathological Analysis, Erbil, Kurdistan Region, \\ Iraq \\ *corresponding author: alewi1987@gmail.com
}

Bulletin UASVM Animal Science and Biotechnologies 76(1)/ 2019

Print ISSN 1843-5262; Electronic ISSN 1843-536X

DOI:10.15835/buasvmcn-asb: 2018-0030

\begin{abstract}
Brucellosis is a global zoonotic bacterial disease. It is also an ever-increasing public health concern, particularly in endemic regions such as Kurdistan region in Middle East. Samples of meat juice were screened for anti-Brucella antibodies via Rose Bengal Test (RBT) and ELISA from January to June 2018. Bacteriological isolation of Brucella sp. from meat samples was also performed. The overall prevalence of bovine brucellosis is $7.7 \%, 6.6 \%$, and $4.9 \%$ by RBT, ELISA, and culture-based test respectively. Based on sensitivity and specificity, ELISA outperforms RBT in comparison to culture results as the gold standard test. Nonetheless, both tests showed good efficiency in comparison to culture approach. In terms of temporal changes of brucellosis rate, spring progress is strongly associated $\left(\mathrm{r}^{2}=0.96\right)$ with increase in seroprevalence. In conclusion, the prevalence of bovine brucellosis in Erbil city is alarming. Countermeasures should be taken to mitigate the economic losses and transmission to human.
\end{abstract}

Keywords: Temporal changes, Brucella abortus, Brucella melitensis, Sensitivity, Specificity

\section{Introduction}

Brucellosisis a highly contagious global zoonotic disease caused by Brucella sp. that have the ability to invade macrophages, dendritic cells, epithelia, and placental trophoblasts (de Figueiredo et al., 2015).This bacterial genus comprises different species that have wide range of animal hosts which facilitates the spread of the disease among humans as well as different domestic and wild animals (Ghaderinia \& Shapouri, 2017). Brucella infection (Brucellosis) is mainly an infection offood-producinganimals including large and small ruminants. It is recognized by the World Organization for Animal Health (OIE) as a class B animal epidemic (Casalinuovo et al., 2016; Addis and Desalegn, 2018; AL-mashhadany, 2018a).

Different species of Brucella tend to be hostspecific.Brucellae aregram-negative coccobacilli with straight or slightly curved, facultative intracellular,nonspore forming, non-motile, and non-capsulated cells (Waringa et al., 2016; Patel et al., 2017). Out of twelve species, the most implicated agents of brucellosis are B.abortus, $B$. melitensis, B. bovis, B.canis, and B.suis (Scholz et al., 2016; Sabrina et al., 2018).

Brucellosis has adverse effects on animals and humans as well as economic implications for individuals and communities. Indeed, brucellosis can inflict high economic costs in terms of medical tests, treatment, and worker absence, which makes it also a considerable social problem particularly in developing nations. It also induces fear in the community, which can negatively affect the global trade of meat, milk, and their products (Mufinda et al., 2017; Raghava et al., 2017).

The transmission of brucellosis to humans occurs through different ways. Ingestion of contaminated raw or undercooked meat from infected animals and unpasteurized milk or 
milk products are the most common routes of infection acquisition. Transmission also occurs through skin wounds or mucous membranes following direct contact with animal-derived contaminated materials (de Figueiredo et al., 2015). Respiratory, genital, and mother-toinfant transmission is also reported (Najum, 2014;Ali et al., 2015; AL-Shemmari, 2018).

Epidemiologically, World Health Organization (WHO) estimates that 500,000 new cases occur annually, however, this value is expected to represent one-fifth of all cases (Khan et al., 2001; Raghava et al., 2017) with high prevalence in countries of the Mediterranean basin, the Middle East including Iraq, Arabian Peninsula,Africa,Asia, Central and South Americas(CDC, 2017; AL-mashhadany, 2018b).Recently, Jaff (2016) reported that the prevalence of human brucellosis among governorates of Kurdistan region is higher than recorded from adjacent countries.The study also reported occurrence rates of $6.36 \%$ in 2011 in Dohuk, 10.7\%in Erbil city in 2012, and an annual incidence rate of 976 cases per 100,000 of population were recorded in Sulaymaniyah governorate in 2013.

Nationwide studies of bovine brucellosis in developing countries are scarce. In fact, prevalence of brucellosis in livestock in many developing countries is alarming as reflected by the high numbers documented in epidemiology reports of the past decade. Cattle sero prevalence estimates have been observed to range between 3\% and 15\% (Godfroid et al., 2011 and references therein). For instance, in Bangladesh, the overall bovine prevalence is 3.7\% $(2.1 \%-66 \%$ confidence interval) (Islam et al., 2013), while in Egypt, according to the General Organization of Veterinary Service (GOVS), the prevalence of bovine brucellosis dropped from $1.27 \%$ in 2002 to $0.35 \%$ in 2011 (Wareth et al., 2014).

Since the early appreciation of Brucella as the causative agent of brucellosis, a number of serological diagnostic tests were developed. Serological tests are generally divided into three categories: (i) the classical or conventional tests [such as RBT, Complement Fixation (CF), Milk Ring Test (MRT)], (ii) primary binding assays [such as Radioimmunoassay and ELISA] and (iii) developing technology [PCR assays] (best reviewed in Godfoid et al., 2010; Poester et al., 2010).Little is known about the role of meat and its products in transmission of Brucella to human. Therefore, the objectives of this work are to determine the occurrence of Brucella antibodies and Brucella speciesin red meat samplesfrom markets of Erbil City. The sensitivity, specificity and total efficacy of RBT and ELISA in comparison to traditional culture-based approach was also investigated.The relationship between the prevalence of anti-Brucella antibodies in red meat with months during the period of study was also addressed.

\section{Materials and Methods \\ 1- Study Design and Sampling}

Three hundred and fifty (350) meat samples were collected from cattle carcasses during the period from January to June 2018.Sample units comprise 115 thigh muscles, 125 lumber lymph nodes (L.Ns), and 110 shoulder musclesfrom different retail butchers in Erbil city.Each sample weighted about 50-100 grams separately collected in sterile polyethylene bags and rapidly transported to Laboratory of Microbiology, Pathological Analysis Department, Knowledge University, Erbil City in ice box with a minimum delay. Upon arrival, samples were immediately deep-frozen and stored at $-20^{\circ} \mathrm{C}$ up to one week.

\section{2- Preparation of Meat Juice}

According to Wallander et al., (2015), after one week of deep freezing, samples were thawed at $20-25^{\circ} \mathrm{C}$. About $2-5 \mathrm{ml}$ of meat juices were collected in an Eppendorf tube and separated by centrifugation into two parts; for RBT and ELISA assays.

\section{3- Detection of Brucella antibodies}

A- Rose Bengal Test (RBT)

Equal quantities of antigen and meat juice sample were mixed on a clean slide by a stirring stick. The slide was manually rotated for 3-4 minutes and inspected for any level of agglutination. When observed, the RBT was considered positive.

\section{B - ELISA}

The ELISA tests were performed according to a published protocol.

\section{4- Isolation of Brucella}

The isolation of Brucella from meat samples was done under sterile conditions at the Microbiology Laboratory, Pathological Analysis Department, following standard procedures 
Table1. Occurrence of Brucella antibodies among meat juice according to RBT and ELISA tests.

\begin{tabular}{cccc}
\hline \multirow{2}{*}{ Type of meat } & \multirow{2}{*}{ No. Examined } & \multicolumn{2}{c}{ Positive samples n (\%) } \\
\cline { 3 - 4 } & & RBT & ELISA \\
\hline Thigh muscle & 115 & $9(7.8)$ & $7(6.1)$ \\
\hline Lumbar L.Ns & 125 & $12(9.6)$ & $11(8.8)$ \\
\hline Shoulder muscle & 110 & $6(5.5)$ & $5(4.5)$ \\
\hline Total & $\mathbf{3 5 0}$ & $\mathbf{2 7 ( 7 . 7 )}$ & $\mathbf{2 3 ( 6 . 6 )}$ \\
\hline L. Ns; Lymph nodes. & & &
\end{tabular}

Table 2. Isolation of Brucella species from different types of meat.

\begin{tabular}{ccccc}
\hline \multirow{2}{*}{ Type of meat } & \multirow{2}{*}{ No. examined } & $\begin{array}{c}\text { Positive isolates } \mathbf{n} \\
\text { (\%) }\end{array}$ & \multicolumn{2}{c}{ Isolates of Brucella species n (\%) } \\
\cline { 4 - 5 } & & $5(4.3)$ & $3(60.0)$ & $2(40.0)$ \\
\hline Thigh muscle & 115 & $9(7.2)$ & $6(66.7)$ & $3(33.3)$ \\
\hline Lumbar L.Ns & 125 & $3(2.7)$ & $2(66.7)$ & $1(33.3)$ \\
\hline Shoulder muscle & 110 & $\mathbf{1 7}(\mathbf{4 . 9})$ & $\mathbf{1 1}(\mathbf{6 4 . 7 )}$ & $\mathbf{6}(\mathbf{3 5 . 3})$ \\
\hline Total & $\mathbf{3 5 0}$ & &
\end{tabular}

(Corbel et al., 2006).The plates of Brucella agar (HiMedia, India) were incubated aerobically and in the presence of $5 \%-10 \%$ carbon dioxide at $37^{\circ} \mathrm{C}$ up to 10 days with daily inspection for the presence of bacterial growth.

\section{5- Identification of Brucella}

Theidentification of B.abortus and B. melitensis were confirmed by traditional biochemical tests (Tille, 2018).

\section{ELISA}

6- Sensitivity and Specificity of RBT and

The sensitivity and specificity of RBT and ELISA were calculated using the bacterial isolation diagnostic method as the gold standard.

\section{7- Statistical analysis}

Data were analyzed using the SPSS software version 21.Confidence intervals of prevalence were estimated using normal distribution approximation at alpha level of 0.05. Confidence intervals for sensitivity, specificity and accuracy are "exact" Clopper-Pearson confidence intervals.

\section{Results}

\section{Seroprevalence of Brucellosis}

Of the 350 meat samples, 27 (7.7\%) were positive by RBT assay. The result shows that the highest rate of Brucella antibodies was found in lumber lymph nodes (9.6\%), while the lowest occurrence rate of Brucella antibodies was in shoulder muscles (5.5\%). On the other hand, the overall prevalence of Brucella antibodies in different types of meat samples according to ELISA is $6.6 \%$. The highest rate of occurrence of Brucella antibodies was found in lumbar L.Ns. 8.8\% (Table1).

\section{Detected Brucella species}

In terms of culture-based diagnosis, it was found that only $4.9 \%$ of the samples were culturepositive for Brucella isolates. It's obvious that $B$. abortus is more prevalent than $B$. melitensis among the evaluated meat samples. The distribution of the isolated Brucella spp.in various meat samples is summarized in Table 2 . It should be noted that approximately 53\% (9/17) of Brucella isolates were recovered from lymph nodes samples.

\section{Assessment of RBT and ELISA Performance}

Compared to traditional culture approach, RBT has a good specificity (97\%) but low sensitivity (62.9\%). On the contrary, the ELISA test has higher specificity and sensitivity (Table 3). Despite low sensitivities of both RBT and ELISA, their accuracy (efficiency) is high (94\% and $97.6 \%$ ) in comparison to the results of culture method.

\section{Temporal changes in Brucella seroprevalence}

For a period of six months, the highest rate of seropositive samples was found in June $7 / 60(11.7 \%)$, while the lowest rates were found in March3/58(5.2\%) and January 3/ 60 (5.0\%). A 
Table 3. Comparison between RBT and ELISA capabilities in detecting brucellosis in meat juice samples

\begin{tabular}{ccc}
\hline Test & Rose Bengal test (95\% CI) & ELISA (95\% CI) \\
\hline Sensitivity & $62.9 \%(42.4-80.6)$ & $71.4 \%(29-96.3)$ \\
\hline Specificity & $97 \%(94.7-98.6)$ & $98.2 \%(96.2-99.3)$ \\
\hline PVP & $62.9 \%(46.4-76.9)$ & $45.45 \%(24.9-67.6)$ \\
\hline PVN & $97.1 \%(95.3-98.2)$ & $99.4 \%(98.1-99.8)$ \\
\hline Efficiency & $94.6 \%(91.8-96.7)$ & $97.6 \%(95.4-98.9)$ \\
\hline Bacteriological culture approach is the gold standard for evaluation.
\end{tabular}

Table 4. Relationship between Months and Prevalence of Brucella antibodies (RBT) during period of study.

\begin{tabular}{ccc}
\hline Month & Total Examined & Positiven (\%) \\
\hline January & 60 & $3(5.0)$ \\
\hline February & 57 & $5(8.8)$ \\
\hline March & 58 & $3(5.2)$ \\
\hline April & 60 & $4(6.7)$ \\
\hline May & 55 & $5(9.1)$ \\
\hline June & 60 & $7(11.7)$ \\
\hline Total & $\mathbf{3 5 0}$ & $\mathbf{2 7}(7.7)$ \\
\hline
\end{tabular}

strong correlation $\left(\mathrm{r}^{2}=0.96\right)$ was found between spring progress (March to June) and increased seropositivity (Fig.1). Based on this sample, 4 $5.2 \%$ of meat samples in Erbil markets will be positive for RBT ( $95 \% \mathrm{CI})$.

\section{Discussion}

Brucellosis is mainly a disease of food producing animals such as cattle, buffalo, camels, sheep, goats, swine, but transmission to humans occurs in several ways most commonly by foodborne route(AL-mashhadany, 2018a; Islam et al., 2018;Zheng et al., 2018).Accurate and rapid detection of brucellosis is crucial for both health and economic purposes. Bacteriological isolation of brucellae from tissues and milk specimens is the only mean of definitive diagnosis of bovine brucellosis. However, culture-based diagnosis is not always feasible especially in field or in slaughterhouses. Alternatively, other serological tests were developed and put in practice. Each test has its own advantages and disadvantages which render the test more or less adopted (Poester et al., 2010).Rose Bengal Test (RBT) is commonly used to detect

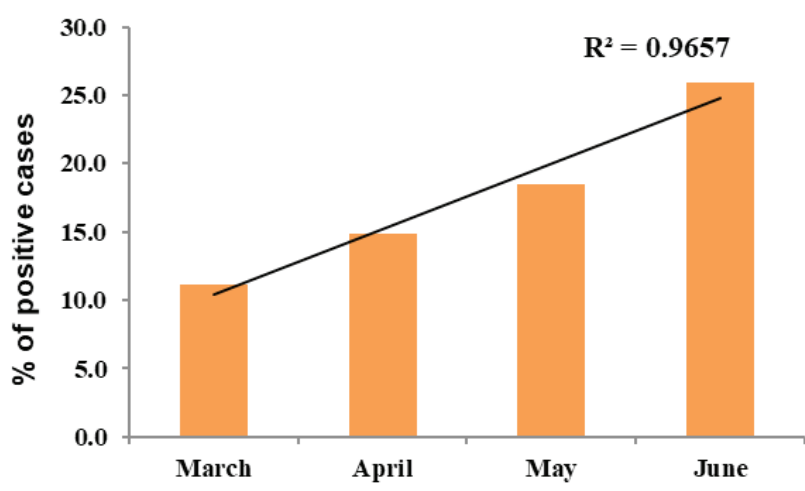

Figure 1. Correlation between spring and seroprevalence of bovine brucellosis

anti-Brucella antibodies in the blood due to its low cost and simplicity. Meanwhile, meat juice can be used in serological assays to monitor the presence of infectious diseases, particularly brucellosis within the food chain (Hammed,1996;Szulowski et al., 2000; Wallander et al., 2015).

According to the available literature, this study seems to be the first in Kurdistan region, Iraq, to address the screening of Brucella sp. in cattle meat. The study has documented a high prevalence of brucellosis in various types of cattle meat samples via RBT and ELISA tests (Table 1).The overall prevalence of Brucella antibodies in juice from all collected meat samples according to RBT was $7.7 \%(27 / 350)$, which is slightly lower than the rate foundin Italy (9.3\%) and in Egypt (11.1\%) according to RBT (Casalinuovo et al., 2018; Salem et al., 2014). However, according to ELISA, Brucella seroprevalence documented in the present study is $6.6 \%(23 / 350)$.Yet, a lower prevalence of brucellosis in Pakistan was reported to be $3 \%$ by RBT and $3.2 \%$ by i-ELISA (Shafee et al., 2012). In contrast, in sub-Saharan region of Africa, a higher rate of Brucella seroprevalence in cattle was estimated to be $16.2 \%$ (10.2 $25 \%, 95 \% \mathrm{CI}$ ) according to RBT (Mangen et al., 
2002). Furthermore, a higher prevalence rate was reported in an Indian serological study (Trangadia et al., 2009).They also showed that ELISA detected higher rates of brucellosis in cattle than RBT. The prevalence in different regions ranged from $6.2 \%$ $-56.4 \%$ according to ELISA. On the other hand, the prevalence according to RBT ranged from $42.3 \%$ $-2.7 \%$.

In terms of evaluation of employed serological tests, ELISA assay outperforms RBT (Table 3). This finding is in good agreement with previous reports (Konstantinidis et al., 2007; Weiner et al., 2010). Indeed, RBT has been reported to produce false positiveresultsin responseto Yersiniaenterocolitica or Leptospira infections (Mainar-Jaime et al., 2005; Munoz et al., 2005). Nonetheless, another study claims that serum agglutination, Coombs, competitive ELISA, Brucellacapt, lateral flow immunochromatography, immunoprecipitation, and ELISA did not outperform RBT in screening of brucellosis (Díaz et al., 2011).However, a recent study of brucellosis in cattle found RBT and ELISA to be the most suitable diagnostic sero tests due to their high sensitivity and specificity (Matope et al., 2011).

Meat juice samples were found equivalent to sera as a material for ELISA-based diagnosis but such high correlation in results was obtained for samples from hares rather than cattle (Szulowski et al., 2000), consequently, a cautious view should be held in generalizing the findings.

The overall isolation rate for brucellae from different meats is $4.9 \%(17 / 350)$ (Table 2). The finding of about 53\% (9/17) of Brucella isolates were from lymph nodes sample is consistent with Brucella tendency to invade macrophages which are abundant in lymph nodes as a part of the immune response to the infection (de Figueiredo et al., 2015).The abundance of brucellae in samples of lymph nodes was also reported in Egypt (Ali and Mahdey, 2010) and in Iran (Faham et al., 2014). The same study also showed that B. melitensis was isolated from edible offal of serologically positive slaughtered cattle at Beni- Suef slaughterhouse constituting $40 \%, 50 \%, 15 \%, 20 \%, 15 \%$ and $50 \%$ for Liver, Spleen, Lung, Kidney, Heart and lymph nodes respectively. Moreover, nearly analogous findings were reported by El Nesser et al., 2007. Differences in frequency of Brucellae isolation from various organs and from several species may be attributed to the alterations in stage of infection as well as the efficiency of microbiological methods used for isolation of the organism.

Szulowski and colleagues (2013) in Poland, studied the bacteriological investigations of cattle slaughtered during period 2002 - 2011. Serum and tissues samples from 176 cows were examined. All sera were RBT and SAT positive, while in bacteriological examination, B. abortus was not isolated, Brucella suis biovar 2 were was isolated from 5 cows. Furthermore, Faham and associates (2014) in Iran reported that $11.38 \%$ and $13.01 \%$ of blood and Lymph nodes samples were positive for Brucella species. The study also indicated that $3.2 \%$ and $1.6 \%$ of camel lymph nodes samples were positive for $B$. abortusand $B$. melitensis respectively.

The temporal distribution of seropositive meat samples from cattle carcasses (Table 4) shows strong association with spring progress (Figure 1).The possible cause of gradual increase in the seropositive rates of brucellosis in meat samples is still difficult to draw. First, the documented rates during study period are based on RBT test that could give false positive results. However, if the infection occurred previously in latewinter, subsequent gradual increase of antibodies during spring may account for the increase of serpositivity rate despite external environmental factors. Indeed, the real cause(s) is not currently known. Another point worth mentioning is that these findings contradict very recent observations of increase in seropositive cases during spring (AL-mashhadany, unpublished data).These observations are likely due to the gradual decrease in temperature, humidity, and rain level in Kurdistan region during months of spring. For instance, wet season was found to be a risk factor for seropositive brucellosis in cattle carcasses (Megersa et al., 2012).Indeed, the decrease in Brucella seroprevalence in Erbil among cattle and buffalo populations during spring has been recently foundin tested milk samples(ALmashhadany, unpublished data).

\section{Conclusion}

The prevalence of bovine brucellosis in Erbil city is still high which may pose a serious threat to human health an economic growth. Indeed, transmission to farmers, butchery personnel and consumers of meat is highly expected; consequently, meat should be analyzed before 
marketing. Despite being specific, RBT showed a low sensitivity in detecting brucellosis in meat juice samples which may hinder its usefulness as a rapid, straightforward, and affordable screening test. As a result, a search for an equivalent, affordable, and sensitive agglutination test form eat juice is recommended. Lymph nodes are the most samples harbored B. abortus and B. melitensis. Therefore, special care in proper cooking should be mounted among consumers to prevent transmission to humans. Spring is associated with gradual increase in Brucella seroprevalence. Environmental factors (temperature, humidity, etc) that may contribute to the epidemiology of bovine brucellosis are recommended to be investigated.

Funding: This work was funded by the Knowledge University under grant No. 2576.

\section{References}

1. Addis SA, Desalegn AY (2018). Comparative Sero epidemiological Study of Brucellosis in Sheep under Smallholder Farming and Governmental Breeding Ranches of Central and North East Ethiopia. J Vet Med. Doi:10.1155/2018/7239156.

2. Ali S, Akhter S, Neubauer H, Melzer F, Khan I, Ali Q Irfan M (2015). Serological, cultural, and molecular evidence of Brucella infection in small ruminants in Pakistan. The Journal of Infection in Developing Countries, 9:470-475.

3. AL-mashhadan, DA (2018a). Zoonotic Diseases. (Part Two). Bacterial Diseases 1- Brucellosis. Lambert Academic Publisher.

4. AL-mashhadany DA (2018b). The Utility of MRT to Screen Brucellosis Among Ewe and Nanny Goats Milk in Erbil Governorate/ Kurdistan region/ Iraq. International Journal of Biology,Pharmacy, and Apllied Science, 7:17861802.

5. Tille PM (2018). Bailey and Scott's Diagnostic Microbiology. (14th ed.). Missouri: Mosby Elsevier (Chapter 35).

6. AL-Shemmari IGM (2018). Comparative study between conventional and molecular tests to detect the incidence of brucellosis in cattle and buffaloes in Babylon and Karbala provinces. Scientific Journal of Medical Research, 2:7-13.

7. Casalinuovo F, Ciambrone L, Cacia A, Rippa P (2016) Contamination of bovine, sheep and goat meat with Brucella spp. Ital J Food safety. Doi: 10.4081/ ijfs.2016.5913.

8. CDC (Centers for Disease Control and Prevention). Brucellosis Reference Guide: Exposures, Testing, and Prevention. (2017). https://www.cdc.gov/brucellosis/ pdf/brucellosi-reference-guide.pdf/Accessed 04.08.18.

9. Corbel MJ, Alton GG, Banai M (2006). Brucellosis in humans and animals: Produced by theWorld Health Organization in collaboration with the Food and
Agriculture Organization of the United Nations and World Organisation for Animal Health. Health WHO/CDS/EPR. Available from: http://www.who.int/csr/resources/ publications/Brucellosis.pdf/Accessed 04.08.18.

10. De Figueiredo P, Ficht TA, Rice-Ficht A, Rossetti CA, Adams LG (2015). Pathogenesis and immunobiology of brucellosis: review of Brucella-Host Interactions. AmericanJournalof Pathology, 185:1505-1517.

11. Díaz R, Casanova A, Ariza J, Moriyon I (2011) The Rose Bengal Test in human brucellosis: a neglected test for the diagnosis of a neglected disease. PLoS Negl TropDis.5(4):e950. Doi: 10.1371/journal.pntd.0000950.

12. El-Nesser KA, Mahdy E, Shalaby A, Deeb S (2007). Pathological and immunohistochemical studies on Brucella melitensis in cows. VeterinarymedicineJournalGiza, 55:275-292

13. Faham K, Rahimi E, Shakerian A, Doosti A, Momtaz H (2014). Molecular study of the prevalence of Brucella abortus and Brucella melitensis in the blood and lymph node samples of slaughtered camels by polymerase chain reaction (PCR) in Iran. Acta Veterinaria, 64:245-256.

14. Godfroid J, Nielsen K, Saegerman C (2010). Diagnosis of brucellosis in livestock and wildlife. CroatianMedical Journal, 51(4): 296-305.

15. Godfroid J, Scholz HC, Barbier T, Nicolas C, Wattiau P, Fretin D, Whatmore AM, Cloeckaert A, Blasco JM, Moriyon I, Saegerman C (2011). Brucellosis at the animal/ ecosystem/human interface at the beginning of the 21st century. PreventiveVeterinaryMedicine, 102:118-131.

16. Hammed DA (1996). Hygienic Importance of Brucella melitensis in the Meat of Sheep and Goats. Ph.D. Thesis. Baghdad University, College of Veterinary Medicine and Surgery, Public Health Department, Baghdad, Iraq.

17. Islam M, Khatun M, Saha S, Basir M, Hasan MM (2018) Molecular detection of Brucella spp. from milk of seronegative cows from some selected area in Bangladesh. J Pathog. Doi: 10.1155/2018/9378976.

18. Jaff D (2016). Brucellosis in Iraqi Kurdistan: an overview. Journal of Entomology and Zoological Studies, 4:11131115.

19. Ghaderinia P, Shapouri R (2017). Assessment of immunogenicity of alginate microparticle containing Brucella melitensis $16 \mathrm{M}$ oligo polysaccharide tetanus toxoid conjugate in mouse. Banat's Journal of Biotechnology, 8:83-92.

20. Khan MY, Mah MW, Memish ZA (2001). Brucellosis in pregnant women. ClinicalInfectious Diseases, 32:11721177.

21. Konstantinidis A, Minas A, Pournaras S, Kansouzidou A, Papastergiu P, Maniatis A, Stathatis N, Hadjichristodoulou C (2007).Evaluation and comparison of fluorescence polarization assay with three of the currently used serological testsin diagnosis of human brucellosis. European Journal of Clinical Microbiology \& Infectious Diseases, 26:715-721.

22. Mainar-Jaime RC, Muñoz PM, de Miguel MJ, Grilló MJ, Marín CM, Moriyón I, Blasco JM (2005). Specificity dependence between serological tests for diagnosing bovine brucellosis in Brucella-free farms showing false 
positive serological reactions due to Yersinia enterocolitica O: 9. CanadianVeterinary Journal, 46:913-916.

23. Mangen MJ, Otte J, Pfeiffer D, Chilonda P (2002) Bovine brucellosis in sub-Saharan Africa: estimation of seroprevalence and impact on meat and milk offtake potential. FAO Livestock policy discussion paper.(8):53. Available from: http://www.fao.org/3/a-ag274e.pdf/Accessed 11.08.18.

24. Matope G, Muma JB, Toft N, Gori E, Lund A, Nielsen K, Skjerve E (2011). Evaluation of sensitivity and specificity of RBT, c-ELISA and fluorescence polarisation assay for diagnosis of brucellosis in cattle using latent class analysis. Veterinary Immunology and Immunopathology, 141:58-63.

25. Megersa B, Biffa D, Abunna F, Regassa A, Godfroid, J, Skjerve E (2012). Seroepidemiological study of livestock brucellosis in a pastoral region. Epidemiology and Infection, 140:887-896.

26. Mufinda FC, Boinas F, Nunes C (2017). Prevalence and factors associated with human brucellosis in livestock professionals. Revista de Saude Publica.51,57. Doi:10.1590/S1518-8787.2017051006051

27. Munoz PM, Marin CM, Monreal D, Gonzalez D, GarinBastuji B, Diaz R, Mainar-Jaime RC, Moriyon I, Blasco JM (2005). Efficacy of several serological tests and antigens for diagnosis of bovine brucellosis in the presence of falsepositive serological results due to Yersinia enterocolitica 0: 9. Clinical and Diagnostic Laboratory Immunology, 12:141-151.

28. Najum AA (2014). Diagnosis of Brucella melitensis infection in goats milk by milk ring test \& Polymerase chain reaction. Magazine of Al-Kufa University Biology, 6:198-201.

29. Patel KB, Chauhan HC, Patel SS, Patel BK, Shrimali MD, Patel AC, Chandel BS (2017). Detection of Brucella antibodies in sheep with special aspect of clinical status and breed. AdvancedAnimalVeterinary Sciences, 5:486490.

30. Poester FP, Nielsen K, Samartino LE, Yu WL (2010). Diagnosis of Brucellosis. Open VeterinaryScienceJournal, 4:46-60.

31. Raghava S, Gowda MHM, Shome R, Kulkarni M, Umesha S (2017). Epidemiological and Molecular Characterization of Brucella Species in Cattle. Asian Journal Animal Science, 11:123-131.

32. Sabrina R, Mossadak TH, Bakir M, Asma M, Khaoula B (2018). Detection of Brucella spp. in milk from seronegative cows by real-time polymerase chain reaction in the region of Batna, Algeria, Veterinary World, 11:363367.

33. Salem LMS, Khoudair MR, Osman SA (2014). SeroDiagnosis of Brucellosis by Using Simple and Rapid Field Tests with Emphasis on Some Possible Risk Factors in Humans. GlobalVeterinary, 12:320-325.

34. Scholz HC, Revilla-Fernández S, Al Dahouk S, Hammerl JA, Zygmunt MS, Cloeckaert A, Koylass M, Whatmore AM, Blom J, Vergnaud G, Aistleitner K, Hofer E, Witte A (2016). Brucella vulpis sp. nov., isolated from mandibular lymph nodes of red foxes (Vulpes vulpes). InternationalJournal of Systematic andEvolutionaryMicrobiology, 66:2090-2098.

35. Shafee M, Rabbani M, Ahmad MU, Muhammad K, Sheikh AA, Awan MA, Shabbir MZ, (2012). Seroprevalence of bovine brucellosis using indirect ELISA in Quetta Balochistan, Pakistan. JAPS, Journal of Animal and Plant Science, 22: 125-127.

36. Szulowski K, Iwaniak W, Weiner M, Zlotnicka J (2013). Brucella suis biovar 2 isolations from cattle in Poland. Annals ofAgricultural and EnvironmentalMedicine, 20 672-675.

37. Szulowski K, Pilaszek J, Iwaniak W (2000). Application of meat juice in diagnosis of brucellosis in hares and wild boars by ELISA. Bulletin-veterinary Institute in Pulawy, 44(1): 45-52.

38. Trangadia B, Rana SK, Mukherjee F, Srinivasan VA (2010). Prevalence of brucellosis and infectious bovine rhinotracheitis in organized dairy farms in India. Tropical Animal Health Production, 42, 203-207.

39. Wallander C, Frössling J, Vågsholm I, Burrells A, Lundén A (2015). "Meat juice" is not a homogeneous serological matrix. Foodborne pathogens andDisease, 12:280-288.

40. Wareth G, Hikal A, Refai M, Melzer F, Roesler U, Neubauer $\mathrm{H}$ (2014). Animal brucellosis in Egypt. Journal of Infection in DevelopingCountries, 8:1365-1373.

41. Waringa NA (2016). A Comparative Study of Diagnostic Assays and Risk Factors Associated With Human Brucellosis Transmission In Baringo County, Kenya. M.Sc. Thesis, University of Nairobi, Kenya.

42. Weiner M, Iwaniak WO, Zlotnicka J, Szulowski K. (2010). Diagnosis of bovine brucellosis using traditional serological techniques and fluorescence polarisation assay. Bulletin-veterinary Institute in Pulawy, 54:485-488.

43. Zheng R, Xie S, Lu X, Sun L, Zhou Y, Zhang Y, Wang K (2018). A Systematic Review and Meta-Analysis of Epidemiology and Clinical Manifestations of Human Brucellosis in China. BioMed ResInt.Doi: 10.1155/2018/5712920 